June 17, 2021

\title{
Support for Border Security During the COVID-19 Pandemic: Evidence on Levels and Predictors from Eight Western Democracies in 2020
}

\author{
Marie Fly Lindholt, Frederik Jørgensen, Alexander Bor \& Michael Bang Petersen* \\ Department of Political Science, Aarhus University, DK-8000 Aarhus C, Denmark \\ *Corresponding author: michael@ps.au.dk
}

\begin{abstract}
One of the unprecedented measures to contain the spread of COVID-19 during the first wave of the pandemic was to close borders across the world. In Europe the closing of national borders were perceived as particularly controversial because of the emphasis of the free movement across borders of labor and citizens within the European Union. Here, we examine the level of support for border closings among citizens from eight Western democracies, how support developed over time, and how particular COVID-19-related concerns and considerations predict individual differences in support. Specifically, we collected data on support for tightened border security from April 9, 2020 until December 19, 2020 in quota-sampled online surveys in Denmark, Sweden, United States, United Kingdom, France, Germany, Italy and Hungary. Eight Western democracies that differ in their response to and the impact of COVID-19 ( $\mathrm{N}=67,679)$. Overall, the data show moderate to high levels of support for tightened border security across all observed countries, with substantial within-country variation. Furthermore, the analyses show that support for border security relates to both usual predictors of anti-immigration views and corona-specific considerations, in particular, personal concerns about the adverse effects of COVID-19 and attributions of blame to international actors such as China and WHO.
\end{abstract}

Acknowledgements: The data has been collected as part of the HOPE project (www.hope-project.dk), funded by The Carlsberg Foundation (grant CF20-0044 to Michael Bang Petersen). We are grateful for research assistance from Magnus Storm Rasmussen.

Published in Journal of Elections, Public Opinion and Parties. Please reference the published version: https://doi.org/10.1080/17457289.2021.1924743 
Across most of the world, borders were closed to contain the spread of COVID-19 during the first wave of the pandemic, creating an unprecedented situation of restrictions on travel not seen since World War II (New York Times, 2020). These border closures fueled significant political discussion. Governments were criticized for lacking health-scientific support for the decision of border closures (DR, 2020) and in the European Union, where the free movement of labor and citizens is a key value, the closure of borders was particularly controversial (JP, 2020). Moreover, the consequences of border closings were multiple and intrusive - both at the societal and individual level and may have worsened the ongoing recession caused by the COVID-19 pandemic (BBC, 2020). Nonetheless, for many countries, enhanced border security was in place for most of 2020, in particular as infections again increased in the fall of 2020.

In this manuscript, we present a descriptive analysis of support for tightening border security during the COVID-19 pandemic across eight western democracies. Furthermore, we investigate both individual-level predictors of support for border security and macro-level predictors of border security. Overall, our analyses suggest that especially three perspectives are relevant to understand public support for border security during the COVID-19 pandemic: (1) vote choice, (2) an anti-internationalization perspective, and (3) egotropic concern. Thus, respondents who voted for a right-wing party or candidate, respondents who blame China or WHO for the severity of the corona-crisis, and respondents who are concerned for the consequences of the corona-crisis for themselves and their families are more supportive of tightening border security. Enhanced border security during the pandemic was thus supported by a coalition of voters combining those traditionally in favor of tight border control and those particularly concerned about the personal consequences of the pandemic.

\section{Potential Predictors of Support for Border Security During the COVID-19 Pandemic}

So far, no studies have investigated the specific corona-related concerns and considerations that affect the support for border security during the COVID-19 pandemic. Yet, the debate of border security is not a new topic in neither Europe nor the United States, especially in the context of immigration debates. To identify potential predictors of support for border security during the COVID-19 pandemic, we therefore draw on research on the sociodemographic predictors of attitudes on border security in the context of immigration policy. In addition, we outline a number of relevant COVID-19 specific concerns and attributions of blame that may be associated with support for border security during the pandemic. 
From research on immigration policy attitudes, we know that several demographic characteristics are associated with support for anti-immigration policies such as border security. First, conservative voters are more likely to support anti-immigration policies compared to liberal voters (Fennelly \& Federico, 2007). Second, several studies have found that age and education are associated with immigration policy attitudes, while the effect of gender is less pronounced in research on immigration policy attitudes (ibid.). Specifically, older and lower educated individuals are more likely to support restrictive immigration policies (ibid.). Third, low income is also associated with support for more restrictionist immigration policies (Young et al., 2018). On this basis, we include sex, age, education, income and vote choice as demographic predictors in our model.

Turning to COVID-19 specific factors, we examine two country-level factors: The actual policy restrictions on international travel (see further description below) and the severity of the pandemic (Hale et al., 2020). At the individual-level, one factor that has received much scholarly attention is fear. Since the outbreak of the COVID-19 pandemic, national polls indicate sharp increases in fear and worries related to the coronavirus (Mertens et al., 2020; Asmundson \& Taylor, 2020). Furthermore, we know that perceptions of threat are crucial determinants of protective behavior during the COVID-19 pandemic (Jørgensen et al., 2020). However, it is plausible that feelings of fear affect, not just your own behavior, but also attitudes on how to cope with the threat as a nation. From research on terrorism, we know that fear of terrorism is associated with support for counter-terrorism policies; such as increased border security (Vorsina et al., 2019). Thus, it is likely that feelings of fear during a crisis such as the COVID-19 pandemic also predict attitudes on how to cope with this specific threat. Consequently, we expect corona-related fear to predict support for border security during the COVID-19 pandemic. Following a standard distinction within public opinion research (Lewis-Beck \& Paldam, 2000), we investigate the role of two categories of corona-related fear: egotropic and sociotropic concerns. While egotropic concerns relate to the consequences for yourself and your family, sociotropic concerns include consequences at the societal level, such as the country's economy and the capacity of the health care sector.

In public opinion research, another key factor beyond egotropic and sociotropic concerns are attributions of blame. In essence, the question of: Who is responsible? (Iyengar, 1994). Prior research shows that attributions of blame are particularly likely in the midst of crises (Douglas, 2013), where blame attributions help manage public uncertainty by attributing negative events to "an external enemy, or even individuals who defy existing beliefs" (Nagarajan, 2020). Since border security is a potential way of reducing uncertainty from external actors and also a way of restricting behavior of individuals from your own society, we accordingly expect attributions of blame to be associated with support for border security. Our blame attribution measurements (see detailed discussion below) tap who/what are to blame for the severity of the corona crisis. As such, it is important to note that this conception of attributing blame to external actors overlaps with work on COVID-19 conspiracies that view some of 
our attribution measurements as COVID-19 conspiracies. On a general note, both the US and China have blamed each other for the spread of SARS-CoV-2. While some conspiracy theories have argued that SARS-CoV-2 is a bioweapon designed in a Chinese laboratory (Imhoff \& Lamberty, 2020), Chinese officials have participated in the spread of conspiracy theories arguing that SARS-CoV-2 was introduced to China by the US army (The Scientist, 2020). Thus, the need to attribute blame in the midst of crises such as the COVID-19 pandemic overlaps clearly with the use of conspiracy theories as a tool to attribute blame to external enemies.

\section{Materials and methods}

Data

We fielded approximately nationally representative surveys in eight countries from April 9, 2020 until December 19, 2020: Denmark, Sweden, the United Kingdom, the United States of America, Italy, France, Germany and Hungary (please see Table A1 in the Online Appendix (OA) for an overview of the data collection). The survey was conducted in accordance with the guidelines of the Danish National Committee of Health Research Ethics for conducting survey-based research involving human subjects and all participants provided informed consent. In each of the eight countries, the survey company Epinion sampled adult respondents using online panels. Survey respondents were quota sampled to match the population margins on age, gender, and geographic location in each of the eight countries. We address remaining imbalances by post-stratifying our sample data to match the demographic margins from the population.

Countries were chosen to represent a diversity of national responses to the COVID-19 pandemic as well as a diversity in the severity of the local epidemic. To illustrate differences in government strategies regarding border security specifically, we utilize the sub-measure of the policy stringency index (Hale et al., 2020) that focuses specifically on border security (see next section for measurement). Figure 1 plots the development in border security stringency as a function of time over the survey period (Hale et al., 2020; see also below). To illustrate the severity of the local epidemic, we utilize the registered count of daily COVID-19 cases per capita (Hale et al., 2020). Additionally, Figure 1 also plots aggregate support for tightening border security as a function of time (see next section for measurement).

As seen in Figure 1, there is substantial variation in the severity of the epidemic across the countries in our sample with the United States following the most severe trajectory while Germany follows the least severe development in this period. Furthermore, we observe large increases in the daily cases per capita between October and December 2020 across all countries in the sample. Moreover, 
while all countries have implemented some stringent measures, there is also substantial variation in the level of restrictions on international travel across countries. Focusing first on the variation between countries, we observe the highest level of restrictions at the beginning of the time period (April 9) in Denmark, Germany and Hungary. By the end of the time period (December 19), Hungary maintained the position as the most restrictive when it came to international travel restrictions while both Denmark and Germany had loosened their policies. Moving to within country developments over time, we observe substantial variation across the countries. In both Sweden, the United States and France the levels of international travel restrictions have been relatively constant throughout 2020 . On the contrary, we observe the largest variation over time in Italy and the United Kingdom. Independent of the level of restrictions on international travel as well as the severity of the local epidemic, we observe moderately high to very high levels of support for border security across all countries.

\section{Figure 1: Selection of countries for data collection}
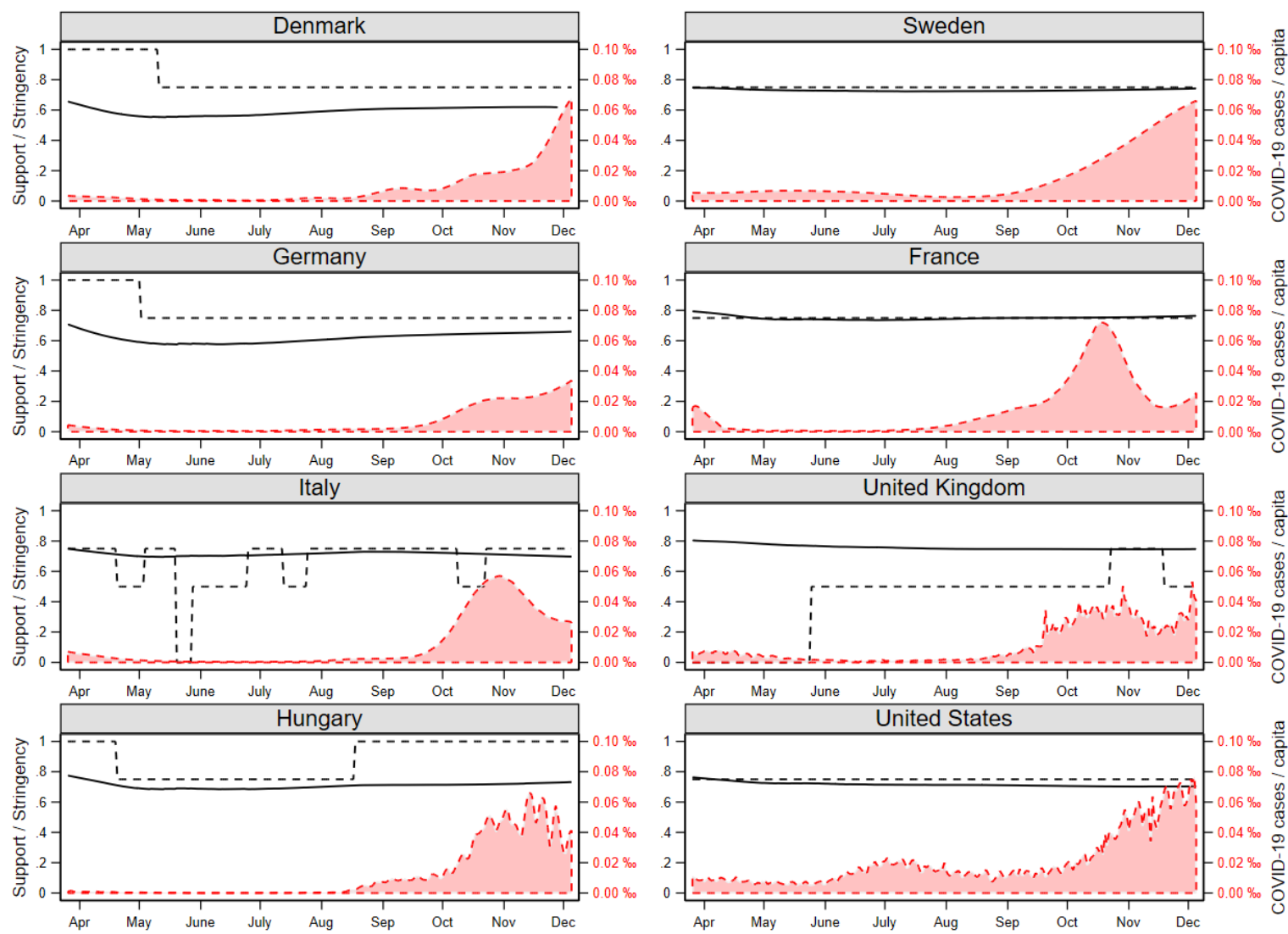

Note: Solid lines are the developments in support for tightening border security. Dashed lines are the developments in restrictions on international travel. Red bars are the developments in the daily COVID19 case counts per capita. 


\section{Measures}

We measure our outcome, support for tightening border security, by asking respondents the following question: "We should tighten border security given the current circumstances". Respondents answered on a 5-point scale from "completely disagree" to "completely agree". The question is rescaled to range from 0 to 1 , with higher values indicating higher level of support for tightening border security.

To assess macro-level predictors of support for border security, we measured the stringency of restrictions on international travel using the Oxford COVID-19 Government Response Tracker (Hale et al., 2020). Restrictions on international travel is measured using an ordinal scale with the following categories: (0) no restrictions, (1) screening arrivals, (2) quarantine arrivals from some or all regions, (3) ban arrivals from some regions, and (4) ban on all regions or total border closure. We rescale this measure to a continuous measure ranging from $0-1$, with higher values indicating a higher level of restrictions on international travel. In the OA (Figure A5), we provide a sensitivity analysis using Hale et al's. (2020) overall measure of policy stringency instead of the specific sub-measure that focuses on international travel restrictions. This overall measure is a composite measure of the number of nonpharmaceutical interventions taken in a specific country (e.g. school closings, curfews and restrictions on international travel). The index is scaled from 0 to 1 , with higher values indicating a higher level of stringency of the government response. To measure the severity of the local epidemic, we utilize the registered count of COVID-19 confirmed cases per capita. These numbers are also taken from the Oxford COVID-19 Government Response Tracker dataset. We recalculate this measure to a measure of new COVID-19 cases per capita per day, instead of the cumulative measure of COVID-19 cases. Again, we scale the measure to range from 0 to 1 , with higher values indicating a higher level of COVID-19 infected cases per capita.

To assess individual-level predictors of support for border security, we first measured worry using five questions measuring the extent to which respondents are concerned about the consequences of the COVID-19 pandemic. The questions wordings are "To what degree are you concerned about the consequences of the corona-virus... (1) for you and your family?, (2) for hospitals' ability to help the sick?, (3) for society's ability to help the disadvantaged?, (4) on social unrest and crime?, and (5) on the country's economy?". Respondents answered these five questions on 4-point scales from "not at all" to "to a high degree". In the main analyses, we treat these factors as continuous variables and scale them to range from 0 to 1 , with higher values indicating higher levels of concern.

Second, we measure attributions of blame using seven questions regarding who/what are to blame for the severity of the corona crisis. The questions are: "In your opinion, why did the corona crisis become so severe? Please select all that applies: (1) because China covered up its severity, (2) because the government did not take it seriously enough, (3) because the government cared too little 
about the economic consequences of the crisis, (4) because the coronavirus is a new disease, that we do not know enough about, (5) because the World Health Organization was incompetent in communicating about the virus, (6) because lay individuals did not take the virus seriously enough, (7) because the media created mass hysteria". The respondents answered either "Yes" or "No" to each of the seven statements. In the estimations, each of the blame variables are therefore entered as indicator variables (0 for no, 1 for yes).

Finally, we measured sex, age, education, income and vote choice. Sex is an indicator variable ( 0 for males; 1 for females). Age is a continuous variable asking respondents how old they are. Age is rescaled from $0-1$, with 0 being the minimum age in the sample (18 years) and 1 being the maximum age (100 years). Education is an indicator variable based on the internationally comparable ISCEDscale ( 0 for non-tertiary education; 1 for tertiary education). Income is a continuous measure ranging from $0-1$, with higher values indicating a higher income. Vote choice is a dummy indicating whether the respondent voted for a left- or right-wing party/candidate at the last first order election $(0$ for left wing party/candidate; 1 for right wing party/candidate).

Table A2 in the OA reports the descriptive statistics for all the above correlates in our overall sample. Moreover, Figure A1 in the OA shows an overview of all bivariate correlations.

\section{Statistical analysis}

To answer the research question, we regress support for tightening border security on the individuallevel and macro-level predictors described above. Specifically we run four models. Across all four models, we pool data from all countries. To account for the fact that observations are nested within countries, all models include country dummies and the use of standard errors that are clustered by country. The first model is an individual-level model that only includes the individual-level predictors beyond the country dummies. In the second model, we add time dummies (i.e., dummies for each data round) to the first model to account for any common time-specific trends in the estimated associations. In the third model, we move on to modelling both the individual-level and macro-level predictors specified above. In particular, we add restrictions on international travel and COVID-19 confirmed cases to model 1. In other words, we are modelling whether within country differences in restrictions and confirmed cases, over time, relates to support for international travel restrictions. In the fourth model, we add time dummies to the third model - again to control away any common time trends in the variables.

Furthermore, we conduct two sensitivity analyses in the OA. First, we replicate the analysis while treating the 4-point scale measures of concern as categorical variables instead of continuous (see 
Figure A4 in the OA). Second, we replicate the analysis using an overall measure of stringency of government response instead of the measure of restrictions on international travel (see Figure A5 in the OA). The results are essentially similar to those presented in the main text.

Given that both the outcome and predictors are scaled to range between $0-1$, the size of the estimated coefficients reported below reflects the percentage points change in support for tightening border security when we compare individuals at the minimum and maximum values for each of the correlates, respectively.

\section{Results}

Figure 2 shows the distribution of support for tightening border security, by country. For the descriptive analysis below we refer to the percentage who support border security (i.e. share of respondents who answered "Somewhat agree" or "Completely agree" to the question: "We should tighten border security given the current circumstances". This percentage refers to the level of support for border security for the full analysis period, i.e. April 2020 - December 2020. Overall, we see a high level of support for tightening border security in most of the countries in our sample. Except for Denmark and Germany, the distribution is highly skewed towards support for border security, while we observe a moderately positive level of support in Denmark and Germany. More specifically, we see the highest level of support in the United Kingdom (77\%). Furthermore, we observe high support levels in both France (75 $\%$ ), Hungary (70 \%), the United States (68 \%), Sweden (67\%) and Italy (67\%). As noted, we observe a more moderate level of support in Denmark (52\%) and Germany (54 \%). While Figure 2 generally shows a high level of support for restrictions on international travel, it simultaneously depicts that there is also substantial individual-level variation in support. 
Figure 2: Support for border security
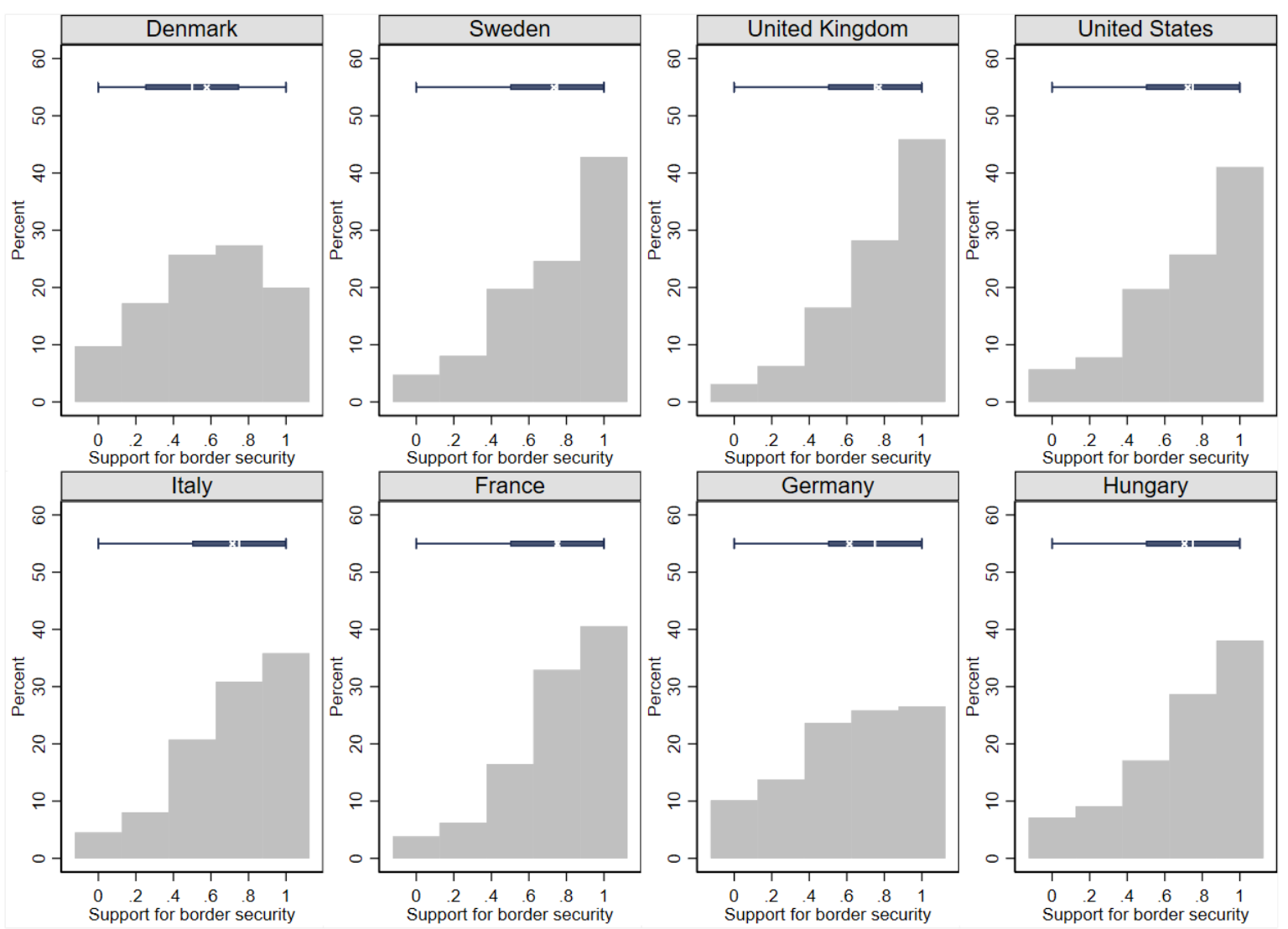

Note: Histograms: display the distributions of support for border security, by country. Boxplots: boxes hold the 25th-75th percentile, white bars are median values, white crosses are mean values, while whiskers are minimum and maximum values.

On this basis, we turn towards understanding the individual-level and macro-level predictors of support for tightening border security. Table 1 presents the results from the statistical analyses described above. Below, we specifically focus on Model IV, where we pool all data from all countries and model the both the individual-level and the macro-level predictors simultaneously while also including country and time dummies (for robustness, Figure A2 in the OA provides models where we assess demographics, concern and blame separately). Note that Table 1 also reports the three other models discussed in the statistical analysis section. Results from these models are consistent with the findings from Model IV. 
Figure 3: Individual-level and macro-level correlations of support for border security

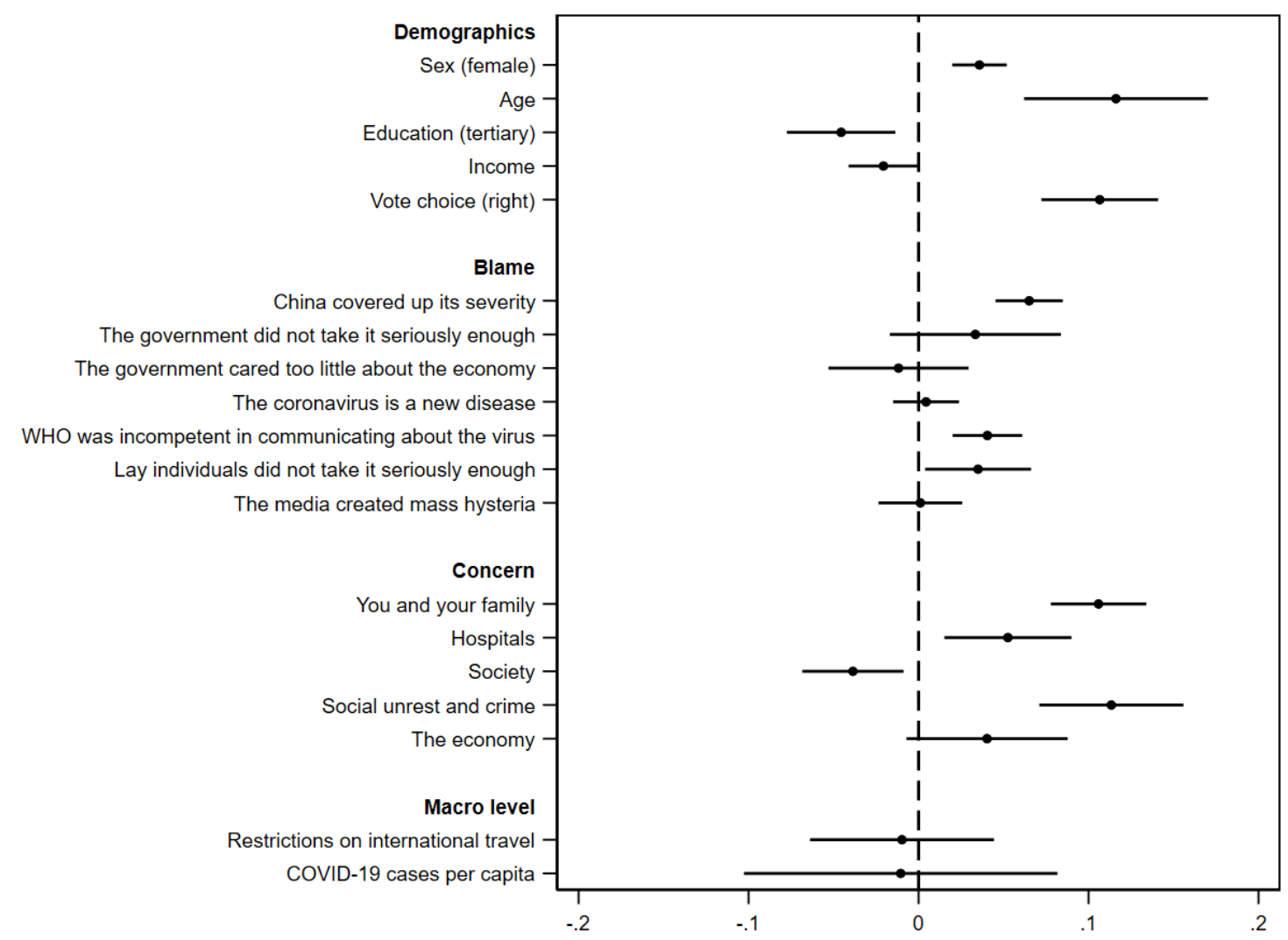

Note: $N=67,679$. Black circles are the estimated correlations based on model IV in Table 1. The model includes country dummies and dummies for each data round. Horizontal lines are the associated $95 \%$ confidence intervals.

Focusing on demographics, we observe that vote choice is a strong predictor of support for border security. Specifically, respondents who report that they voted for a right-wing party or candidate are 11 percentage points $(95 \% \mathrm{CI}: 7-14)$ more supportive of tightening border security compared to respondents who reported voting for at left-wing party or candidate. Furthermore, we see that age is a similarly strong positive predictor of support for border security. When we compare respondents at the minimum and maximum level of age in the sample, the difference is 12 percentage points (95\% CI: 617). We also observe a small gender difference, with females being 4 percentage points (95\% CI: 2-5) more supportive of border security compared to males. Finally, respondents with tertiary education and high income are 5 (95\% CI: 1-8) and 2 (95\% CI: 0-4) percentage points less supportive of tightening border security, respectively, compared to respondents with non-tertiary education and respondents with the lowest level of income.

Among the corona-related considerations, we first look at the different measures of attribution of blame. Here we observe the strongest predictor being the opinion that the severity of the epidemic 
can be blamed on China covering up the severity of the crisis. Specifically, respondents who blame China for the severity of the crisis are 7 percentage points (95\% CI: 5-8) more supportive of border security compared to respondents who did not blame China. Furthermore, blaming the World Health Organization (WHO) for the severity of the crisis is also a significant and positive predictor of support for border security. Respondents who blame WHO are 4 percentage points (95\% CI: 2-6) more supportive of border security compared to respondents who did not blame WHO. Finally, respondents who report that they blame lay individuals for the severity of the crisis are 4 percentage points $(95 \%$ CI: 0-7) more supportive of border security compared to respondents who did not blame lay individuals.

Focusing on the corona-specific concerns, we find egotropic concerns to be a strong predictor of support for border security. Those who are the most concerned about the consequences of the corona crisis for themselves and their families are 11 percentage points (95\% CI: 8-13) more supportive of border security compared to the least concerned respondents. For the different types of sociotropic concern, we observe different associations with support for border security. Respondents who are the most concerned about the consequences of the corona crisis for the hospitals' ability to help the sick are 5 percentage points (95\% CI: 2-9) more supportive of border security compared to the least concerned respondents. Furthermore, concern for the consequences on social unrest and crime is also a significant positive predictor of support for border security: The most concerned are 11 percentage points $(95 \% \mathrm{CI}$ 7-16) more supportive compared to the least concerned respondents. Whereas the above concern measure positively predicts support for border security, concerns over the consequences for society's ability to help the disadvantaged emerges as a negative predictor. Hence, we observe that the most concerned are 4 percentage points (95\% CI: 1-7) less supportive of border security compared to the least concerned. The only concern measure that is not statistically significantly related to border security support is concern about the country's economy. These results are also supported by the sensitivity test replicating the analysis with categorical concern variables (see Figure A4 in the OA).

Turning attention to the two macro-level predictors, we observe that both the development of national restrictions on international travel and the development in the local epidemics (i.e., new COVID-19 cases per capita) are statistically unrelated to support for border security. All the results above are also supported by the additional models in Table 1 (Model I-Model III).

Overall, these results suggest that especially three perspectives - including vote choice, an antiinternationalization perspective, and egotropic concern - are relevant to understanding support for border security during the COVID-19 pandemic. These main results are essentially similar across all countries in our sample (see Figure A3 in the OA). We finally replicated the results from Model IV above while using the overall policy stringency index (Hale et al., 2020) instead of the sub-measure that focuses on restrictions on international travel (see Figure A5 in the OA). This analysis fully replicates the results presented above. 
Table 1: Individual-level and macro-level predictors of support for border security

\begin{tabular}{|c|c|c|c|c|}
\hline & Model I & Model II & Model III & Model IV \\
\hline \multicolumn{5}{|l|}{ Demographics } \\
\hline Female & $\begin{array}{l}0.035^{* *} \\
(0.007)\end{array}$ & $\begin{array}{l}0.036^{* *} \\
(0.007)\end{array}$ & $\begin{array}{l}0.035^{* *} \\
(0.007)\end{array}$ & $\begin{array}{l}0.036^{* *} \\
(0.007)\end{array}$ \\
\hline Age & $\begin{array}{l}0.118^{* *} \\
(0.023)\end{array}$ & $\begin{array}{l}0.116^{* *} \\
(0.023)\end{array}$ & $\begin{array}{l}0.118^{* *} \\
(0.023)\end{array}$ & $\begin{array}{l}0.116^{* *} \\
(0.023)\end{array}$ \\
\hline Education (tertiary) & $\begin{array}{l}-0.046^{*} \\
(0.013)\end{array}$ & $\begin{array}{l}-0.046^{*} \\
(0.013)\end{array}$ & $\begin{array}{l}-0.046^{*} \\
(0.013)\end{array}$ & $\begin{array}{l}-0.046^{*} \\
(0.013)\end{array}$ \\
\hline Income & $\begin{array}{l}-0.020^{*} \\
(0.008)\end{array}$ & $\begin{array}{l}-0.021^{*} \\
(0.009)\end{array}$ & $\begin{array}{l}-0.020^{*} \\
(0.009)\end{array}$ & $\begin{array}{l}-0.021^{*} \\
(0.009)\end{array}$ \\
\hline Vote choice (right) & $\begin{array}{l}0.107^{* * * *} \\
(0.015)\end{array}$ & $\begin{array}{l}0.107^{* * * *} \\
(0.015)\end{array}$ & $\begin{array}{l}0.107^{* * *} \\
(0.015)\end{array}$ & $\begin{array}{c}0.107^{* * *} \\
(0.015)\end{array}$ \\
\hline \multicolumn{5}{|l|}{ Blame } \\
\hline China covered up its severity & $\begin{array}{l}0.064^{* * *} \\
(0.009)\end{array}$ & $\begin{array}{l}0.065^{* * *} \\
(0.008)\end{array}$ & $\begin{array}{l}0.065^{* * *} \\
(0.009)\end{array}$ & $\begin{array}{l}0.065^{* * *} \\
(0.008)\end{array}$ \\
\hline The government - not seriously enough & $\begin{array}{c}0.033 \\
(0.021)\end{array}$ & $\begin{array}{c}0.033 \\
(0.021)\end{array}$ & $\begin{array}{c}0.033 \\
(0.021)\end{array}$ & $\begin{array}{c}0.033 \\
(0.021)\end{array}$ \\
\hline The government cared too little - economy & $\begin{array}{l}-0.012 \\
(0.018)\end{array}$ & $\begin{array}{l}-0.012 \\
(0.017)\end{array}$ & $\begin{array}{l}-0.012 \\
(0.018)\end{array}$ & $\begin{array}{l}-0.012 \\
(0.017)\end{array}$ \\
\hline A new disease & $\begin{array}{c}0.004 \\
(0.008)\end{array}$ & $\begin{array}{c}0.004 \\
(0.008)\end{array}$ & $\begin{array}{c}0.004 \\
(0.008)\end{array}$ & $\begin{array}{c}0.004 \\
(0.008)\end{array}$ \\
\hline The WHO was incompetent & $\begin{array}{l}0.040^{* *} \\
(0.009)\end{array}$ & $\begin{array}{l}0.041^{* *} \\
(0.009)\end{array}$ & $\begin{array}{l}0.040^{* *} \\
(0.009)\end{array}$ & $\begin{array}{l}0.041^{* *} \\
(0.009)\end{array}$ \\
\hline Lay individuals & $\begin{array}{l}0.037^{*} \\
(0.014)\end{array}$ & $\begin{array}{c}0.035^{*} \\
(0.013)\end{array}$ & $\begin{array}{l}0.036^{*} \\
(0.014)\end{array}$ & $\begin{array}{l}0.035^{*} \\
(0.013)\end{array}$ \\
\hline The media & $\begin{array}{c}0.001 \\
(0.011)\end{array}$ & $\begin{array}{c}0.001 \\
(0.010)\end{array}$ & $\begin{array}{c}0.001 \\
(0.011)\end{array}$ & $\begin{array}{c}0.001 \\
(0.010)\end{array}$ \\
\hline \multicolumn{5}{|l|}{ Concern } \\
\hline You and your family & $\begin{array}{l}0.110^{* * *} \\
(0.012)\end{array}$ & $\begin{array}{l}0.106^{* * *} \\
(0.012)\end{array}$ & $\begin{array}{l}0.111^{* * *} \\
(0.012)\end{array}$ & $\begin{array}{l}0.106^{* * *} \\
(0.012)\end{array}$ \\
\hline Hospitals & $\begin{array}{l}0.062^{* *} \\
(0.017)\end{array}$ & $\begin{array}{l}0.053^{*} \\
(0.016)\end{array}$ & $\begin{array}{l}0.060^{* *} \\
(0.017)\end{array}$ & $\begin{array}{c}0.053^{*} \\
(0.016)\end{array}$ \\
\hline Society & $\begin{array}{l}-0.038^{*} \\
(0.012)\end{array}$ & $\begin{array}{l}-0.039^{*} \\
(0.013)\end{array}$ & $\begin{array}{l}-0.038^{*} \\
(0.013)\end{array}$ & $\begin{array}{l}-0.039^{*} \\
(0.013)\end{array}$ \\
\hline Social unrest and crime & $\begin{array}{l}0.110^{* * * *} \\
(0.018)\end{array}$ & $\begin{array}{l}0.113^{* * *} \\
(0.018)\end{array}$ & $\begin{array}{l}0.110^{* * * *} \\
(0.019)\end{array}$ & $\begin{array}{l}0.113^{* * *} \\
(0.018)\end{array}$ \\
\hline The country's economy & $\begin{array}{c}0.041 \\
(0.020)\end{array}$ & $\begin{array}{c}0.040 \\
(0.020)\end{array}$ & $\begin{array}{c}0.041 \\
(0.020)\end{array}$ & $\begin{array}{c}0.040 \\
(0.020)\end{array}$ \\
\hline \multicolumn{5}{|l|}{ Macro-level } \\
\hline Restrictions on international travel & & & $\begin{array}{c}0.019 \\
(0.051)\end{array}$ & $\begin{array}{l}-0.010 \\
(0.023)\end{array}$ \\
\hline COVID-19 cases per capita & & & $\begin{array}{c}0.052 \\
(0.028)\end{array}$ & $\begin{array}{l}-0.012 \\
(0.033)\end{array}$ \\
\hline Constant & $\begin{array}{l}0.366^{* * *} \\
(0.018) \\
\end{array}$ & $\begin{array}{l}0.382^{* * *} \\
(0.022)\end{array}$ & $\begin{array}{l}0.347^{* * * *} \\
(0.040)\end{array}$ & $\begin{array}{l}0.394^{* * * *} \\
(0.031)\end{array}$ \\
\hline Country dummies & Yes & Yes & Yes & Yes \\
\hline Time dummies & No & Yes & No & Yes \\
\hline $\begin{array}{l}\text { Observations } \\
R^{2}\end{array}$ & $\begin{array}{c}67,679 \\
0.183\end{array}$ & $\begin{array}{c}67,679 \\
0.190\end{array}$ & $\begin{array}{l}67,679 \\
0.183\end{array}$ & $\begin{array}{l}67,679 \\
0.190\end{array}$ \\
\hline
\end{tabular}

Notes: Clustered robust standard errors on country level in parentheses. All models include country dummies. Model II and IV include dummies for each data round. ${ }^{*} p<0.05,{ }^{* *} p<0.01,{ }^{* * *} p<0$. 


\section{Discussion}

In this manuscript, we investigated first the level of support for tightening border security during the COVID-19 pandemic, and second the individual-level and macro-level predictors of support. Overall, the results show moderate to high levels of support for increased border security across the countries in our sample. Furthermore, the analysis suggests that especially three perspectives - including vote choice, an anti-internationalization perspective, and egotropic concern - are relevant to understanding support for border security during the COVID-19 pandemic.

First, consistent with research on immigration attitudes more generally, we found that rightwing respondents were more supportive of tightening border security compared to left-wing respondents. Second, we found that respondents who blame China or the WHO for the severity of the crisis are more supportive of border security. These findings are consistent with the expectation that in the midst of a crisis, blaming external actors fuels a need to do something to reduce uncertainty. Thus, tightening border security can be seen as a way of protecting yourself against external influences that are blamed for the severity of the crisis. Third, we found that egotropic concerns for yourself and your family is the key corona-related concern for understanding support for border security. While concerns about social unrest following the pandemic are important too, other sociotropic concerns about hospital capacity and the economy are not.

These results suggest that feelings of fear are relevant to understand not just protective behavior during the COVID-19 pandemic, but also attitudes on how to cope with the threat as a nation. When considered in tandem with the finding that support for increased border security also relates to sentiments that lay people are not taking the pandemic seriously enough, this suggests that the closing of borders during the first year of the COVID-19 pandemic appealed to a psychological desire to simply do everything possible to protect against a threat that appeared immanent and pervasive.

The role of vote choice and anti-internationalization views for support for border security is consistent with the larger literature on attitudes about border security and immigration, suggesting that parts of the support for stricter border security during the pandemic are motivated by a general preference for such policies. Thus, the relatively high levels of support for border security reflects the emergence of a coalition between those generally in favor of enhanced border security and those concerned about the pandemic. In this regard, however, it is relevant to note that the threats motivating those concerned about the pandemic are different from the threats motivating those generally concerned about immigration. Specifically, we observed ego-tropic concern as a key predictor of support for border security during the pandemic. On the contrary, studies within the immigration literature has shown sociotropic explanations to be clearly more powerful when it comes to assessing the threat from immigration (e.g., Hainmueller et al., 2015). On the one hand, given the role of personal risk- 
perceptions, one might therefore expect that support for border security could decrease throughout the rest of the pandemic due to an expected decrease in personal risk-perceptions as more people are being vaccinated and the risk of infection becomes lower. On the other hand, we have already observed relatively constant levels of support for border security during 2020 across all countries in our sample, while the severity of the pandemic has varied substantially throughout 2020. Thus, one could also expect that the level of support for border security will remain stable and relatively high throughout the pandemic. 


\section{References}

Asmundson, G. J., \& Taylor, S. (2020). Coronaphobia: Fear and the 2019-nCoV outbreak. Journal of anxiety disorders, 70, 102196.

BBC (2020). "Coronavirus: A visual guide to the economic impact". https://www.bbc.com/news/business-51706225

DR (2020). "Mette F. står ved grænselukning trods manglende evidens". https://www.dr.dk/nyheder/politik/mette-f-star-ved-graenselukning-trods-manglende-evidens

Douglas, M. (2013). Risk and blame. Routledge.

Fennelly, K., \& Federico, C. (2008). Rural residence as a determinant of attitudes toward US immigration policy. International Migration, 46(1), 151-190.

Hainmueller, J., \& Hopkins, D. J. (2015). The hidden American immigration consensus: A conjoint analysis of attitudes toward immigrants. American Journal of Political Science, 59(3), 529-548.

Hale, Thomas, Sam Webster, Anna Petherick, Toby Phillips, and Beatriz Kira (2020). Oxford COVID19 Government Response Tracker, Blavatnik School of Government. Data use policy: Creative Commons Attribution CC BY standard.

Imhoff, R., \& Lamberty, P. (2020). A bioweapon or a hoax? The link between distinct conspiracy beliefs about the Coronavirus disease (COVID-19) outbreak and pandemic behavior. Social Psychological and Personality Science, 11(8), 1110-1118.

Iyengar, S. (1994). Is anyone responsible? How television frames political issues. University of Chicago Press.

Jyllands-Posten (2020). "Ministre kritiserer grænselukning og corona-enegang i EU". https://jyllandsposten.dk/international/europa/ECE12008117/ministre-kritiserer-graenselukning-og-coronaenegang-i$\mathrm{eu} /$

Jørgensen, F., Bor, A., \& Petersen, M. B. (2020). Compliance Without Fear: Individual-Level Protective Behavior During the First Wave of the COVID-19 Pandemic.

Lewis-Beck, M. S., \& Paldam, M. (2000). Economic voting: an introduction. Electoral studies, 19(23), 113-121.

Mertens, G., Gerritsen, L., Duijndam, S., Salemink, E., \& Engelhard, I. M. (2020). Fear of the coronavirus (COVID-19): Predictors in an online study conducted in March 2020. Journal of Anxiety Disorders, 102258.

Nagarajan, A. (2020). "What makes people lay blame on others during a crisis". https://www.livemint.com/opinion/online-views/what-makes-people-lay-blame-on-others-during-acrisis-11586277472113.html

New York Times (2020). "Europe Barricades Borders to Slow Coronavirus". https://www.nytimes.com/2020/03/17/world/europe/EU-closes-borders-virus.html 
Taylor, S. (2019). The psychology of pandemics: Preparing for the next global outbreak of infectious disease. Cambridge Scholars Publishing.

The Scientist (2020). Chinese Officials Blame US Army for Coronavirus. https://www.thescientist.com/news-opinion/chinese-officials-blame-us-army-for-coronavirus-67267

Vorsina, M., Manning, M., Sheppard, J., \& Fleming, C. M. (2019). Social dominance orientation, fear of terrorism and support for counter-terrorism policies. Australian Journal of Political Science, 54(1), 99-113.

Young, Y., Loebach, P., \& Korinek, K. (2018). Building walls or opening borders? Global immigration policy attitudes across economic, cultural and human security contexts. Social Science Research, 75, 83-95. 